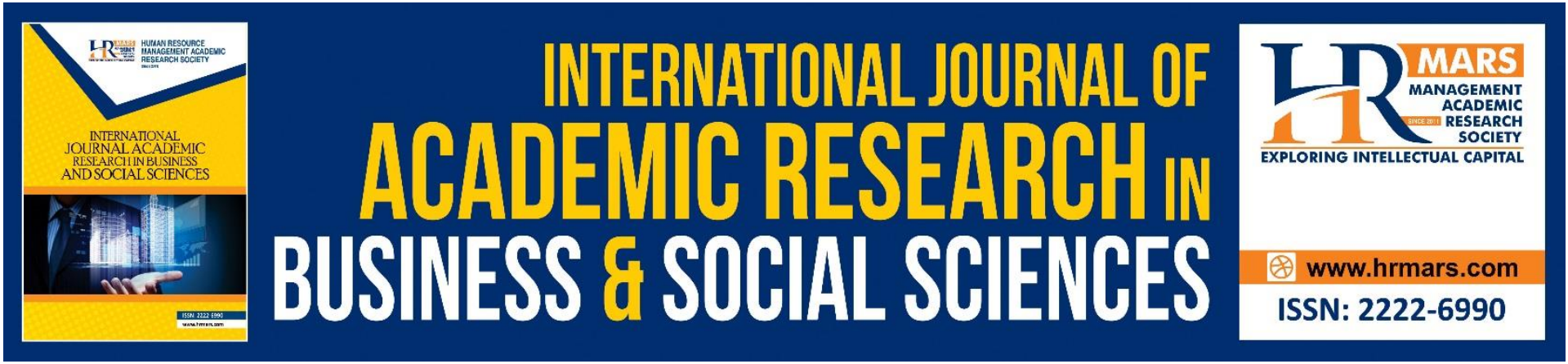

\title{
An Integrated Approach of Analytic Hierarchy Process and Decision-Making Trial and Evaluation Laboratory (AHP- DEMATEL) to Solve the Supplier Selection Problem
}

Nur Dayana Abdul Rahman, Elza Fazwin Mersing, Nur Syafieqah Syazuween Mohd Yazid \& Nor Faradilah Mahad

To Link this Article: http://dx.doi.org/10.6007/IJARBSS/v11-i11/11155 DOI:10.6007/IJARBSS/v11-i11/11155

Received: 07 September 2021, Revised: 09 October 2021, Accepted: 29 October 2021

Published Online: 23 November 2021

In-Text Citation: (Rahman et al., 2021)

To Cite this Article: Rahman, N. D. A., Mersing, E. F., Yazid, N. S. S. M., \& Mahad, N. F. (2021). An Integrated Approach of Analytic Hierarchy Process and Decision-Making Trial and Evaluation Laboratory (AHPDEMATEL) to Solve the Supplier Selection Problem. International Journal of Academic Research in Business and Social Sciences, 11(11), 2279-2299.

\section{Copyright: (c) 2021 The Author(s)}

Published by Human Resource Management Academic Research Society (www.hrmars.com) This article is published under the Creative Commons Attribution (CC BY 4.0) license. Anyone may reproduce, distribute, translate and create derivative works of this article (for both commercial and non0-commercial purposes), subject to full attribution to the original publication and authors. The full terms of this license may be seen at: http://creativecommons.org/licences/by/4.0/legalcode

Vol. 11, No. 11, 2021, Pg. $2279-2299$ 


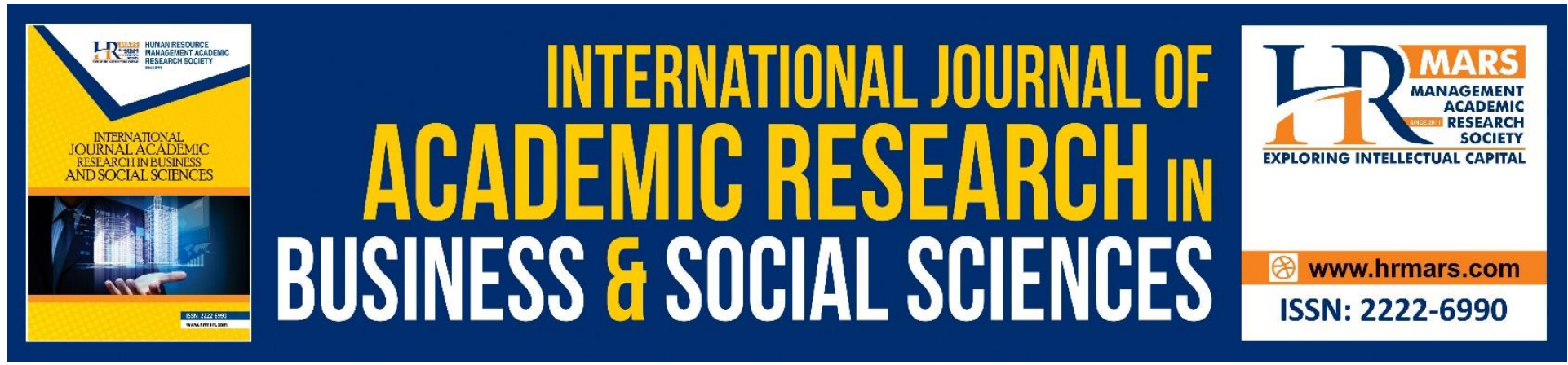

\title{
An Integrated Approach of Analytic Hierarchy Process and Decision-Making Trial and Evaluation Laboratory (AHP-DEMATEL) to Solve the Supplier Selection Problem
}

\author{
Nur Dayana Abdul Rahman, Elza Fazwin Mersing, Nur \\ Syafieqah Syazuween Mohd Yazid \& Nor Faradilah Mahad \\ Faculty of Computer and Mathematical Sciences Universiti Teknologi MARA Cawangan \\ Negeri Sembilan, Kampus Seremban, Persiaran Seremban Tiga/1, Seremban 3, 70300, \\ Seremban, Negeri Sembilan, Malaysia \\ Email: faradilah315@uitm.edu.my
}

\begin{abstract}
It is crucial to select the best supplier for a company because the product development will be affected when the wrong supplier is selected. In this study, the Analytic Hierarchy Process (AHP) method is implemented to choose the best supplier for a printing company. However, the AHP method could not identify the influence among criteria. Therefore, it is integrated with the Decision-Making Trial and Evaluation Laboratory (DEMATEL) method. The objectives of this study are to select the best supplier for a printing company and determining the interrelationship between the criteria by identifying the influences of each criterion to other criteria. A discussion with the decision-maker was held to finalize the criteria and suppliers used in this study. The criteria used are cost (C1), quality (C2), relationship with the supplier (C3), warranty (C4), and machinery safety (C5), while the chosen alternatives are Supplier 1 (S1), Supplier 2 (S2), and Supplier 3 (S3). Experimental results show that the ranking order for the criteria is $\mathrm{C} 1>\mathrm{C} 5>\mathrm{C} 2>\mathrm{C} 4>\mathrm{C} 3$, and the ranking order for the supplier is $\mathrm{S} 2>\mathrm{S} 3>\mathrm{S} 1$, which concludes that $\mathrm{S} 2$ is the best supplier to supply the printing machine to the company. As for the interrelationship between criteria, the criterion that highly influences the other criteria is quality (C2), and the less influential criterion is the warranty (C4). To conclude, the proposed method is appropriate in selecting the best supplier since the findings correspond to the decision maker's choices. Furthermore, this method provides relevant information to the decision-maker about the interrelationship between each criterion and which criterion should be given more attention.
\end{abstract}

Keywords: Multi-Criteria Decision-Making (MCDM), Analytic Hierarchy Process (AHP), Decision-Making Trial and Evaluation Laboratory (DEMATEL) 


\section{Introduction}

Hashmi et al (2021) stated that one of the most explored and important fields in the optimization model is the supplier selection problem. The decision-making process of supplier selection becomes more complicated due to the various criteria that need to be considered when making a decision (Raut et al., 2011). Effective decision-making is necessary when the environment is getting more complicated (Raut et al., 2011). Supplier selection gives a significant impact on a company's financial and operational structure and thus, wrong supplier selection could lead to the destruction of the company's financial and operational structure (Hashmi et al., 2021). Therefore, selecting the best supplier in a complex real-life problem requires a multi-criteria decision-making (MCDM) method.

MCDM is the form of a set of multiple criteria, alternatives, and comparisons in some procedures. MCDM methods have been a fast-growing field of engineering and management (Hendriks et al., 1992). It is mostly used in safety and risk management areas that contemplate the criteria, alternatives, or factors that are independent of each other (Yazdi et al., 2020). MCDM problems work by helping decision-makers to make a decision that is often have multiple conflicting criteria. MCDM methods include Analytic Hierarchy Process (AHP), MultiObjective Optimization on The Basis of Ratio Analysis (MOORA), The Technique for Order of Preference by Similarity TO Ideal Solution (TOPSIS), and Decision-Making Trial and Evaluation Laboratory (DEMATEL). This study used an integrated AHP-DEMATEL method in selecting the best supplier for a printing company.

AHP method is used to help decision-makers in determining the best alternative in a scenario that is influenced by multiple criteria (Patnaik et al., 2020). This method can rank the alternatives and identify the consistency of the expert's judgment of an inconsistent pair-wise comparison matrix that indicates the decision-makers lack an understanding of the problem (Liu et al., 2020). This method helps the decision-makers and experts in getting accurate results as this method prioritizes the most important criterion in choosing alternatives. However, the AHP method is lacking in knowing the interrelationship among criteria, and to solve this, the DEMATEL method is used.

The DEMATEL method can extract interrelationship among the criteria contained in a problem quantitatively (Shahraki \& Paghaleh, 2011). The interdependence among criteria can be identified through a causal digraph that shows the contextual relationships between the criteria by using the DEMATEL method (Shieh et al., 2010). This method does not depend on assumption but instead is helping decision-makers identify influences between the criteria and eventually helping the decision-makers to make a proper decision about their problems (Shieh et al., 2010).

Shieh et al (2010) stated that the traditional MCDM methods including the AHP method are assuming the criteria to be mutually independent and thus, it is impossible to know the interrelationship among the criteria. It is particularly important for the decisionmakers to distinguish between the criteria that were a cause and have an effect on the system so that they can determine which criteria they need to focus on more (Mohd et al., 2020). DEMATEL method can provide the cause and effect group in the form of a causal digraph (Falatoonitoosi et al., 2013) and it also utilizes the experts' knowledge to understand interdependences and interrelations between factors better compared to other MCDM methods (Dalvi-Esfahani et al., 2019). This study applied an integrated approach of the AHPDEMATEL method to determine the rank of the criteria and suppliers and to reveal the causal relations among the criteria. 
Thus, the objectives of this study are to select the best supplier for a printing company by using the AHP method and determining the interrelationship between the criteria by identifying the influences of each criterion to other criteria using the DEMATEL method. This study is crucial to understand the integrated approach of AHP-DEMATEL to solve any MCDM problems. There are five sections in this paper which are (1) Introduction, (2) Literature review, (3) Methodology, (4) Result and Discussion, and (5) Conclusion.

\section{Literature Review}

Multi-Attribute Decision-Making (MADM) and Multi-Objective Decision-Making (MODM) are two categories under Multi-Criteria Decision-Making (MCDM) problems (Hendriks et al., 1992; Liou \& Tzeng, 2012). The methods and techniques used in MCDM involve more than one criterion in solving and structuring the decision problems that have diverse and multiple criteria (Nadkarni \& Puthuvayi, 2020). The development of MODM methods is to discover the most preferable solution to a problem involving various conflicting objectives that need to be optimized simultaneously (Zhang \& Lu, 2009). MODM problems can be solved using methods like goal programming model or multiple objectives programming model (Liou \& Tzeng, 2012). Meanwhile, MADM is a method that helps a decision-making process by choosing an optimal alternative from a predetermined number of alternatives with multiple attributes (Kumar, 2018). MADM also includes structure relation methods, weight analysis, and performance aggregated methods (Liou \& Tzeng, 2012). MADM is also known as MultipleCriteria Decision Analysis (MCDA). MCDA has a lot of variations that provide a structure for making a decision such as calculating the relative weights of the criteria by using a complex algorithm (Campos et al., 2020).

In this study, two MCDM methods, namely Analytic Hierarchy Process (AHP) and Decision-Making Trial and Evaluation Laboratory (DEMATEL) method are used to solve the problem. AHP is a technique that helps decision-makers to choose alternatives by considering the measurement of various criteria and factors (Patnaik et al., 2020). AHP uses three basic principles known as decomposition, comparative judgment, and synthesizing (Saaty, 2000). The first basic principle is decomposing the problem into a hierarchical structure where the hierarchical structure is created by placing the goal at the top of the hierarchy, followed by criteria, sub-criteria (if any) decomposed from criteria, and alternatives (R. W. Saaty, 1987). The use of a hierarchical structure in this method is to help the decision-makers be more focused on evaluating the weight of each criterion and sub-criteria (Ishizaka \& Labib, 2009). The sub-criteria depend on the decision-makers whether it is required or not and the most common hierarchy structure used is depicted in Figure 1.
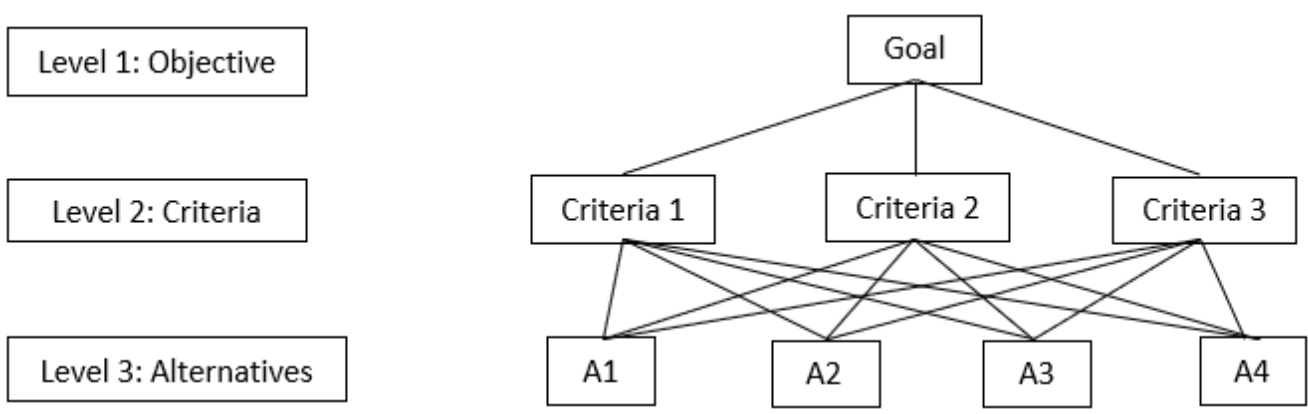

Figure 1. The Hierarchical Structure of AHP Method 
Comparative judgment is where the human judgment is converted into a set of numbers (Demirel et al., 2020) by using the fundamental scale (Saaty, 1990) as in Table 1 and formed into a pair-wise comparison matrix. This principle is used to assess the weight of criteria and alternatives of the system (Mau-Crimmins et al., 2005). The third principle is synthesizing the criteria where several parts or elements are combined into one whole entity. The criteria then will be synthesized to get the final decision known as the best alternatives of the system (Saaty, 1987).

Table 1. The Fundamental Scale

\begin{tabular}{lll}
\hline $\begin{array}{l}\text { Scale of } \\
\text { importance }\end{array}$ & Definition & Elaboration \\
\hline 1 & $\begin{array}{l}\text { Equal Importance } \\
\text { Moderate Importance }\end{array}$ & $\begin{array}{l}\text { Two criteria equally important } \\
\text { One criterion has a moderate } \\
\text { importance over another } \\
\text { One criterion has a strong importance } \\
\text { over another } \\
\text { One criterion has a very strong } \\
\text { importance over another }\end{array}$ \\
7 & Strong Importance & $\begin{array}{l}\text { One criterion has an extremely } \\
\text { importance over another }\end{array}$ \\
9 & Eery Strong Importance & Ese when compromise is needed \\
$2,4,6,8$ & Intermediate Values Between & Use \\
\hline
\end{tabular}

AHP method can be used to help users in solving complex problems by using a simpler step (Karthikeyan et al., 2017). The pair-wise comparison in the AHP method is convenient as it allows decision-makers to approximate the weight of the criteria and can easily compare the alternatives, in other words, the AHP method is user-friendly (Velasquez \& Hester, 2013).

However, AHP has some drawbacks. Human judgment is vague and the decisionmakers may not be able to provide accurate numerical qualities to represent human judgment equally (Karthikeyan et al., 2017). Furthermore, the AHP method cannot evaluate the interdependence between criteria (Ortíz et al., 2016). AHP method can only determine the rank of criteria and alternatives of the system from best to worst by looking at its weight. Thus, to overcome the problem, this study will use a hybrid AHP-DEMATEL method to achieve the objectives of this study.

As shown in Table 2, there are various applications of the AHP method in real life such as making a selection of a suitable machine to increase the manufacturing quality (Chang et al., 2007), choosing the suitable tools to assist the knowledge management (KM) in an organization (Ngai \& Chan, 2005), and selecting the best composite material in designing and developing any structural components (Patnaik et al., 2020). Other than that, the AHP method is used to assess strategies for climate change in the Indian cement manufacturing industry to reduce greenhouse gases emissions (GHGEs) (Balsara et al., 2019) and identifying which criteria is the most important in finding suitable land for maize farming (Tashayo et al., 2020). 
Table 2. The Applications of AHP Method

\begin{tabular}{|c|c|}
\hline Author & Application \\
\hline $\begin{array}{l}\text { Patel and Maniya } \\
\text { (2015) }\end{array}$ & $\begin{array}{l}\text { Selection of wire cut electrical discharge machining } \\
\text { process }\end{array}$ \\
\hline $\begin{array}{l}\text { Ngai and Chan } \\
(2005)\end{array}$ & Tools selection to assist knowledge management \\
\hline Balsara et al (2019) & $\begin{array}{l}\text { Evaluation of strategy in Indian cement } \\
\text { manufacturing industry }\end{array}$ \\
\hline $\begin{array}{l}\text { Horňáková et al } \\
\text { (2019) }\end{array}$ & Selection of appropriate material handling equipment \\
\hline Zoran (2011) & Selection of transportation system in mine planning \\
\hline Chang et al (2007) & Selecting the best slicing machine \\
\hline Demirel et al (2020) & $\begin{array}{l}\text { Selecting the suitable roll stabilizer type for motor } \\
\text { yachts }\end{array}$ \\
\hline $\begin{array}{l}\mathrm{Ng} \text { and Chuah } \\
(2014)\end{array}$ & $\begin{array}{l}\text { Evaluation of design alternatives' environmental } \\
\text { performance }\end{array}$ \\
\hline Patnaik et al (2020) & Composite material selection \\
\hline Tashayo et al (2020) & Producing land suitability maps for maize farming \\
\hline
\end{tabular}

DEMATEL method is immensely helpful to visualize the complicated structure of causal relationships using a digraph. In other words, the relationship between the causeeffect criteria can be converted into an understandable structural model (Falatoonitoosi et al., 2013). This method can improve understanding of a specific problem and could identify the workable solutions with a hierarchical structure, and it is quite different from the AHP method where it only assumes criteria to be independent while the DEMATEL method determines the interdependence between the criteria of a problem via a casual digraph (Shieh et al., 2010). The influence of each criterion in the DEMATEL method is demonstrated as numerical and it helps the decision-makers to identify which criterion influences and are influenced by other criteria (Falatoonitoosi et al., 2013). Table 3 shows a typical range of scales that are used in the DEMATEL method to determine the numerical value of relationships between different criteria according to the experts' opinion (Dalvi-Esfahani et al., 2019).

Table 3. The Range Scale of Linguistic Term

\begin{tabular}{ll}
\hline Scale & Linguistic term \\
\hline 0 & No influence \\
1 & Low influence \\
2 & Medium influence \\
3 & High influence \\
4 & Very High influence \\
\hline
\end{tabular}

Then, the criteria will be separated into two groups: the cause group and the effect group. The criteria in the effect group are influenced by the criteria in the cause group. Therefore, enhancing the cause group will enhance the effect group as well. As a result, this methodology enables decision-makers to reach a high-quality performance regarding the effect group criteria in all fields (Falatoonitoosi et al., 2013). 
The benefit of the DEMATEL method is it can determine which of the components are far more important for the system to remain in the long term (Balsara et al., 2019). The determination of the component's importance is crucial because it helps the decision-makers to identify which criteria that have a significant impact on other criteria (Sumrit \& Anuntavoranich, 2013). DEMATEL is a type of structural modelling method that was used to analyze the causal relationship between criteria of a system (Dalvi-Esfahani et al., 2019). Moreover, the DEMATEL method is a flexible and effective decision-making method to help decision-makers in acquiring more strong decisions (Falatoonitoosi et al., 2013).

One of the applications of the DEMATEL method is in the cement manufacturing industry (Balsara et al., 2019). Other than that, the latest applications are evaluating the interdependence of risk assessment of hydrogen generation unit ( $\mathrm{Li}$ et al., 2020), implementation barriers of social measures and public health to prevent transmission of COVID-19 (Maqbool \& Khan, 2020), identifying critical factors in green mining construction and its policies (Qi et al., 2020), and evaluating the interdependence of big data analytics (BDA) capabilities and its impact on firm performance (Yasmin et al., 2020). The number of articles related to the method in safety and management has increased since the year 2010 and started to increase drastically starting in the year 2015 to 2019 (Yazdi et al., 2020). This indicates that this method is useful enough to be used by the decision-makers to help them solve their problems in various types of fields. Table 4 shows the applications of DEMATEL methods.

Table 4. The Applications of DEMATEL Method

\begin{tabular}{|c|c|}
\hline Author & Application \\
\hline Balsara et al (2019) & $\begin{array}{l}\text { Evaluation of strategy in Indian cement manufacturing } \\
\text { industry }\end{array}$ \\
\hline Chou et al (2012) & $\begin{array}{l}\text { Evaluation criteria of human resource for science and } \\
\text { technology (HRST) }\end{array}$ \\
\hline Dalvi-Esfahani et al (2019) & $\begin{array}{l}\text { Analysing the importance of social media addiction from the } \\
\text { perspective of researchers and psychotherapists }\end{array}$ \\
\hline (Li et al., 2020) & $\begin{array}{l}\text { Evaluating the interdependence of risk assessment of } \\
\text { hydrogen generation } \\
\text { unit }\end{array}$ \\
\hline Maqbool and Khan (2020) & $\begin{array}{l}\text { Implementation barriers of social measures and public health } \\
\text { to prevent transmission of COVID-19 }\end{array}$ \\
\hline $\begin{array}{l}\text { Muhammad and Cavus } \\
\text { (2017) }\end{array}$ & $\begin{array}{l}\text { Identifying learning management system (LMS) evaluation } \\
\text { criteria }\end{array}$ \\
\hline Qi et al (2020) & $\begin{array}{l}\text { Identifying critical factors in green mining construction and its } \\
\text { policies }\end{array}$ \\
\hline Shieh et al (2010) & Identifying the key success factors of hospital service quality \\
\hline Yasmin et al (2020 & $\begin{array}{l}\text { Evaluating the interdependence of big data analytics (BDA) } \\
\text { capabilities and its impact on firm performance }\end{array}$ \\
\hline
\end{tabular}

\section{Methodology}

The AHP method in this study is used to select the best supplier for printing machines while the DEMATEL method is used to identify the influence between criteria by determining the interrelationship among criteria. Thus, the combined technique of AHP-DEMATEL is applied in this study. Figure 2 shows the conceptual diagram of this study. 


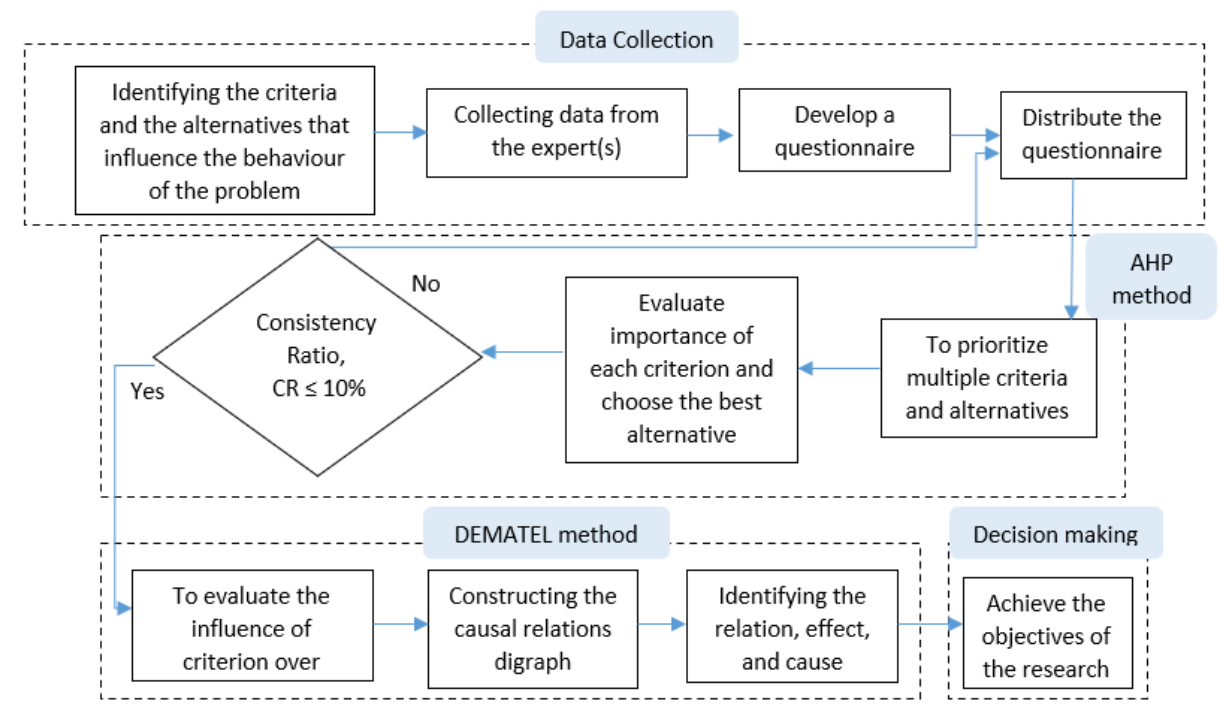

Figure 2. Conceptual Diagram

\section{Framework of AHP Method}

AHP method is known as a user-friendly method (Velasquez \& Hester, 2013) and it is a detailed technique of decision-making process to prioritize the alternatives by considering multiple criteria and factors (Patnaik et al., 2020). The steps listed below shows the procedures of the AHP method (Saaty, 1990):

Step 1. Develop a hierarchical structure

The hierarchical structure is used to analyze the problem. The most common hierarchical structure used as shown in Figure 1.

Step 2. Develop a pairwise comparison matrix, $A$

The scale shown in Table 1 is used as a judgment to make the pairwise comparisons. The pairwise comparison matrix is constructed as follows:

$$
A=\left[a_{i j}\right]=\left[\begin{array}{cccc}
1 & a_{12} & \ldots & a_{1 n} \\
a_{21} & 1 & \ldots & a_{2 n} \\
\vdots & \vdots & \ddots & \vdots \\
a_{n 1} & a_{n 2} & \ldots & a_{n n}
\end{array}\right]
$$

The diagonal is always 1 and the lower triangular matrix is filled using $a_{i j}=\frac{1}{a_{j i}}$. Then, the sum of each column for the pairwise comparison matrix is calculated.

Step 3. Normalize the pairwise comparison matrix

Normalize the pairwise comparison matrix by dividing each element by its column sum.

$$
c_{i j}=\frac{a_{i j}}{\sum_{j=1}^{n} a_{i j}} \text { where } i=1,2,3, \ldots, n \text { and } j=1,2,3, \ldots, n
$$

Then, calculate the sum of each column in the normalized pairwise comparison matrix where it must be equal to 1 .

Step 4. Calculate the weight

Calculate the weight by averaging across the row of the normalized pairwise comparison matrix using 


$$
w_{i}=\frac{1}{n} \sum_{j=1} c_{i j} \text { where } i=1,2,3, \ldots n
$$

Step 5. Check the consistency ratio

Examine the consistencies in the pairwise comparison matrix by computing the Consistency Ratio (CR) value using

$$
C R=\frac{a}{R}
$$

where Consistency Index $(\mathrm{Cl})$ is computed using

$$
a=\frac{\lambda_{\max }-n}{n-1}
$$

$\mathrm{RI}$ is the random consistency index shown in Table 5 and $n$ is the matrix size. The principal eigenvalue, $\lambda_{\text {max }}$, can be obtained by summation of product between the sum of each column in the pairwise comparison matrix and the weight for each attribute. If the value of $C R$ is $\leq$ $10 \%$, the decision maker's judgment is consistent. If the value of CR is higher than $10 \%$, recheck the judgment and identify the problem.

Table 5. Random Consistency Index (RI)

\begin{tabular}{lllllllllll}
\hline $\mathbf{n}$ & 1 & 2 & 3 & 4 & 5 & 6 & 7 & 8 & 9 & 10 \\
\hline $\mathbf{R I}$ & 0.00 & 0.00 & 0.58 & 0.9 & 1.12 & 1.24 & 1.32 & 1.41 & 1.45 & 1.49 \\
\hline
\end{tabular}

\section{Framework of DEMATEL Method}

DEMATEL method is commonly used to identify the influence between criteria to determine the relationship of criteria and thus, the methodology of the DEMATEL method is summarized as below (Shieh et al., 2010):

Step 1. Generate the direct-relation matrix, $A$

This phase measures the relationship between the criteria using the scale shown in Table 3. An $\boldsymbol{M}$ matrix known as a direct-relation matrix will be constructed as $X^{k}=\left\lfloor x_{i j}^{k}\right\rfloor$, where $k$ is the number of experts who participated in the evaluation process with $1 \leq k \leq m$. Thus, $X^{1}, X^{2}, X^{3}, \ldots, X^{m}$ are the elements for the direct-relation matrix of $m$ experts. To consolidate all opinions from $m$ experts, the average matrix $A=\left\lfloor a_{i j}\right\rfloor$ is calculated using

$$
a_{i j}=\frac{1}{m} \sum_{i=1}^{m} x_{i j}^{k}
$$

The direct-relation matrix, $A=\left\lfloor a_{i j}\right\rfloor$ can be generated directly from the questionnaire using the comparison scale when there is only one decision-maker.

Step 2. Set up the normalized direct-relation matrix, $B$

The normalized direct-relation matrix $B=\left\lfloor b_{i j}\right\rfloor$ is set up using

$$
B=\frac{A}{E}
$$

where the values of each element are ranged between $[0,1], C$ is the total sum of elements by row in matrix $A$ and $E$ is the maximum value of $C$.

Step 3. Construct the total-relation matrix, $T$

The total-relation matrix, $T=\left\lfloor T_{i j}\right\rfloor$ of size $\boldsymbol{n} \boldsymbol{n}$ is determined as follows

$$
T=B(I-B)^{-1}
$$


where $I$ is the identity matrix and $B$ is the normalized direct-relation matrix.

Step 4. Find $D, R,(D+R)$, and $(D-R)$

Find $D$ and $R$ using

$$
\begin{aligned}
& D=\sum_{j=1}^{n} T_{i j} \\
& R=\sum_{i=1}^{n} T_{i j}
\end{aligned}
$$

where $D$ is the sum of rows and $R$ is the sum of columns in matrix $T$. Criteria that have positive values of ( $D-R$ ) have a higher influence on the other criteria and are known as cause group. The others with negative values of ( $D$ - R) receive more influence from another and are called the effect group. On the other side, the value of $(D+R)$ indicates the relation degree between each criterion with others.

Step 5. Set up a threshold value, $\alpha$

A threshold value is a level or a point at which something different starts to occur. This value helps experts or decision-makers to eliminate insignificant effects and focus more on the significant effect of the criteria. To compute the threshold value, $\alpha$, calculate the average of elements in matrix $T$ where the total number of elements in matrix $T$ is referred to as $N$ (Sumrit \& Anuntavoranich, 2013).

$$
\alpha=\frac{\sum_{j=1}^{h} \sum_{j=1}^{h}\left[T_{i j}\right]}{N}
$$

Step 6. Produce the causal digraph

The aim of the causal digraph is to visualize how a criterion can affect another. It can be constructed by plotting the coordinates of the cause-effect group ( $D+R, D-R$ ). On the other hand, the criteria included in the causal digraph is the one that has a greater value than the threshold.

\section{Implementation of AHP and DEMATEL Method}

A real-life data about the supplier selection for a printing company located in Johor is used as the case study. The data was collected from a decision-maker who is the manager of the company. The criteria used in this study were cost (C1), quality (C2), relationship with the supplier (C3), warranty (C4), and machinery safety (C5) as shown in Table 6. The decisionmaker then provides three alternatives identified as Supplier 1 (S1), Supplier 2 (S2), and Supplier 3 (S3). The definition of criteria in Table 6 is based on the description provided by the decision-maker. 
Table 6. Definition of Each Criterion

\begin{tabular}{|c|c|}
\hline Criterion & Definition \\
\hline Cost (C1) & $\begin{array}{l}\text { The cost here means that the total price that must be paid for } \\
\text { the machine and the transportation cost in delivering the } \\
\text { machine. }\end{array}$ \\
\hline Quality (C2) & $\begin{array}{l}\text { The quality here refers to the quality of the printing services of } \\
\text { the machine. There are several types of printing machines such } \\
\text { as screen-printing machines, direct-to-Garment printing } \\
\text { machines, heat press printing machines, and other types of } \\
\text { printing machines. Different type of printing machine has } \\
\text { diverse types of quality of the printing services of a machine. }\end{array}$ \\
\hline $\begin{array}{l}\text { Relationship with the } \\
\text { supplier (C3) }\end{array}$ & This criterion refers to the relationship with the supplier. \\
\hline Warranty (C4) & $\begin{array}{l}\text { The printing machine warranty started from the first day of the } \\
\text { purchase made. The longer the warranty period, the better it } \\
\text { is. If the printing machine is defective in the warranty period, } \\
\text { the supplier must repair or replace the machine. }\end{array}$ \\
\hline Machinery safety (C5) & $\begin{array}{l}\text { Machinery safety refers to the safeness of a machine when } \\
\text { doing printing services. Accidents such as lacerations, cuts, and } \\
\text { bruises could happen when dealing with the dangerous } \\
\text { moving part of the printing machine. Therefore, a printing } \\
\text { machine that has proper machinery safety is better. }\end{array}$ \\
\hline
\end{tabular}

A set of questionnaires for both the AHP and DEMATEL methods were constructed and administered to the decision-maker. The data collected was then converted into numeric values using the fundamental scale for the AHP method as shown in Table 1 and the range scale of the linguistic term for the DEMATEL method as in Table 3.

\section{Implementation of AHP Method}

Step 1. Develop a hierarchical structure

The hierarchical structure of the problem is shown in Figure 3.
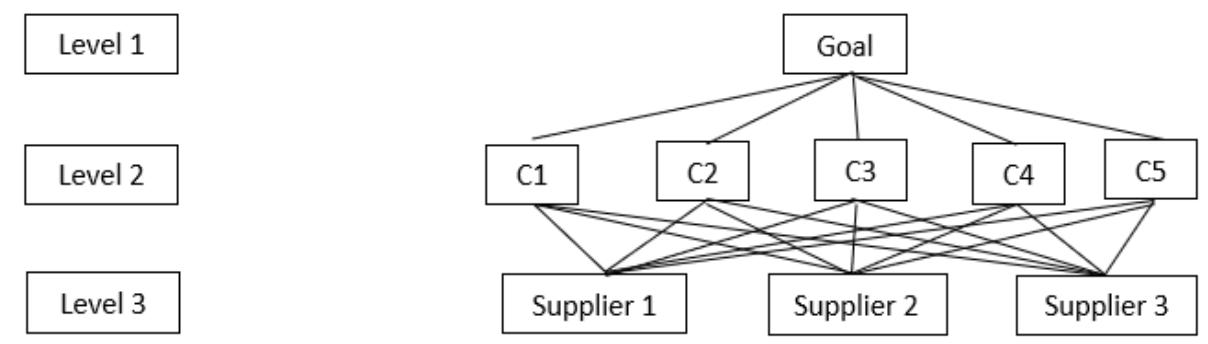

Figure 3. The Hierarchical Structure of the Problem

Step 2. Develop a pairwise comparison matrix

The pairwise comparison matrix for criteria is shown in Table 7. 
Table 7. Pairwise Comparison Matrix of Criteria

\begin{tabular}{|l|l|l|l|l|l|}
\hline Criteria & C1 & C2 & C3 & C4 & C5 \\
\hline C1 & 1 & 3 & 5 & 4 & 1 \\
\hline C2 & $1 / 3$ & 1 & 3 & 5 & 1 \\
\hline C3 & $1 / 5$ & $1 / 3$ & 1 & $1 / 3$ & $1 / 5$ \\
\hline C4 & $1 / 4$ & $1 / 5$ & 3 & 1 & $1 / 3$ \\
\hline C5 & 1 & 1 & 5 & 3 & 1 \\
\hline Sum & $167 / 60$ & $83 / 15$ & 17 & $40 / 3$ & $53 / 15$ \\
\hline
\end{tabular}

Step 3. Normalize the pairwise comparison matrix

The normalized pairwise comparison matrix is constructed by using Equation (2) and can be seen in Table 8. The sum of its columns must be 1 .

Table 8. Normalized Pairwise Comparison Matrix

\begin{tabular}{|l|l|l|l|l|l|}
\hline Criteria & C1 & C2 & C3 & C4 & C5 \\
\hline C1 & $60 / 167$ & $45 / 83$ & $5 / 17$ & $3 / 10$ & $15 / 53$ \\
\hline C2 & $20 / 167$ & $15 / 83$ & $3 / 17$ & $3 / 8$ & $15 / 53$ \\
\hline C3 & $12 / 167$ & $5 / 83$ & $1 / 17$ & $1 / 40$ & $3 / 53$ \\
\hline C4 & $15 / 167$ & $3 / 83$ & $3 / 17$ & $3 / 40$ & $5 / 53$ \\
\hline C5 & $60 / 167$ & $15 / 83$ & $5 / 17$ & $9 / 40$ & $15 / 53$ \\
\hline Sum & 1 & 1 & 1 & 1 & 1 \\
\hline
\end{tabular}

Step 4. Calculate the weight

Table 9 shows the weight for each criterion. The weights are calculated by using Equation (3).

Table 9. Weight of Each Criterion

\begin{tabular}{lll}
\hline Criteria & Weight & $\begin{array}{l}\text { Percentage of weight } \\
(\%)\end{array}$ \\
\hline C1 & 0.355717 & 35.57 \\
C2 & 0.226995 & 22.70 \\
C3 & 0.054505 & 5.45 \\
C4 & 0.094356 & 9.44 \\
C5 & 0.268428 & 26.84 \\
\hline Sum & 1 & 100 \\
\hline
\end{tabular}

Thus, the ranking order for the criteria is $\mathrm{C} 1>\mathrm{C} 5>\mathrm{C} 2>\mathrm{C} 4>\mathrm{C} 3$. It shows that the most important criterion that needs to be considered in selecting the best supplier for the printing machine is the cost (C1) of the machine while the least important criterion is the relationship with the supplier (C3).

Step 5. Check the consistency ratio

First, calculate the value of $\lambda_{\max }$. Then, compute CR by using Equation (4) and (5). The decision-makers' judgment is said to be consistent since the value of CR is $8.68 \%<10 \%$. Step 1-5 is repeated to make a comparison for suppliers with respect to each criterion. The composite weight of the supplier is then calculated to determine the best supplier. Table 10 shows the weight for each supplier with respect to each criterion. The findings show that the ranking order for the suppliers is S2 > S3 > S1. 
Table 10. Weight for Suppliers with Respect to Each Criterion

\begin{tabular}{|l|l|l|l|l|l|l|}
\hline \multirow{2}{*}{ Criteria } & C1 & C2 & C3 & C4 & C5 & \multirow{2}{*}{ Weight } \\
\cline { 2 - 7 } Alternative & 0.355717 & 0.226995 & 0.054505 & 0.094356 & 0.268428 & \\
\hline S1 & 0.071433 & 0.193186 & 0.090909 & 0.090909 & 0.333333 & 0.172271 \\
\hline S2 & 0.748164 & 0.083307 & 0.818181 & 0.818181 & 0.333333 & 0.496316 \\
\hline S3 & 0.180402 & 0.723506 & 0.090909 & 0.090909 & 0.333333 & 0.331413 \\
\hline
\end{tabular}

\section{Implementation of Dematel Method}

Step 1. Generate the direct-relation matrix, $A$

Table 11 shows the direct relation matrix, $A$ by using the scale in Table 3.

Table 11. Direct-relation Matrix, $A$

\begin{tabular}{|l|l|l|l|l|l|l|}
\hline & C1 & C2 & C3 & C4 & C5 & $\begin{array}{l}\text { Sum, } \\
\text { C }\end{array}$ \\
\hline C1 & 0 & 3 & 2 & 1 & 0 & 6 \\
\hline C2 & 4 & 0 & 0 & 2 & 2 & 8 \\
\hline C3 & 2 & 0 & 0 & 0 & 0 & 2 \\
\hline C4 & 0 & 0 & 0 & 0 & 0 & 0 \\
\hline C5 & 0 & 2 & 0 & 0 & 0 & 2 \\
\hline
\end{tabular}

Step 2. Set up the normalized direct-relation matrix, $B$

Table 12 show the normalized direct-relation matrix, $B$ by using Equation (7).

Table 12. Normalized Direct-relation Matrix, $B$

\begin{tabular}{|l|l|l|l|l|l|}
\hline & C1 & C2 & C3 & C4 & C5 \\
\hline C1 & 0 & 0.375 & 0.25 & 0.125 & 0.25 \\
\hline C2 & 0.5 & 0 & 0 & 0.25 & 0.25 \\
\hline C3 & 0.25 & 0 & 0 & 0 & 0 \\
\hline C4 & 0 & 0 & 0 & 0 & 0 \\
\hline C5 & 0 & 0.25 & 0 & 0 & 0 \\
\hline
\end{tabular}

Step 3: Construct the total-relation matrix, $T$

The total-relation matrix, $T$ shown in Table 13 is obtained by using excel solver and Equation (8).

Table 13. Total-relation Matrix, $T$

\begin{tabular}{|l|l|l|l|l|l|}
\hline & C1 & C2 & C3 & C4 & C5 \\
\hline C1 & $\mathbf{0 . 3 5 5 9 3 2}$ & $\mathbf{0 . 5 4 2 3 7 3}$ & $\mathbf{0 . 3 3 8 9 8 3}$ & $\mathbf{0 . 3 0 5 0 8 5}$ & 0.135593 \\
\hline C2 & $\mathbf{0 . 7 2 3 1 6 4}$ & $\mathbf{0 . 3 5 5 9 3 2}$ & 0.180791 & $\mathbf{0 . 4 2 9 3 7 9}$ & $\mathbf{0 . 3 3 8 9 8 3}$ \\
\hline C3 & $\mathbf{0 . 3 3 8 9 8 3}$ & 0.135593 & 0.084746 & 0.076271 & $\mathbf{0 . 0 3 3 8 9 8}$ \\
\hline C4 & 0 & 0 & 0 & 0 & 0 \\
\hline C5 & 0.180791 & $\mathbf{0 . 3 3 8 9 8 3}$ & 0.045198 & 0.107345 & 0.084746 \\
\hline
\end{tabular}

Step 4. Find $D, R, D+R, D-R$

Equation (9) and Equation (10) are used to find $D$ and $R$ for each criterion. Excel solver is used to ease the calculation process. The value of $D, R, D+R$, and $D-R$ are shown in Table 14: 
Table 14. The Effect-Causal Table

\begin{tabular}{|l|l|l|l|l|}
\hline & $\mathbf{D}$ & $\mathbf{R}$ & $\mathbf{D}+\mathbf{R}$ & $\mathbf{D}-\mathbf{R}$ \\
\hline C1 & 1.677966 & 1.59887 & 3.276836 & 0.079096 \\
\hline C2 & 2.028249 & 1.372881 & 3.40113 & 0.655367 \\
\hline C3 & 0.669492 & 0.649718 & 1.319209 & 0.019774 \\
\hline C4 & 0 & 0.918079 & 0.918079 & -0.91808 \\
\hline C5 & 0.757062 & 0.59322 & 1.350282 & 0.163842 \\
\hline
\end{tabular}

Step 5. Set up a threshold value, $\alpha$

The threshold value obtained based on the data is 0.205311 . Equation (11) is used to calculate the threshold value, $\alpha$. Next, compare the threshold value with the elements in matrix $T$. If the value of elements in matrix $T$ is greater than the threshold value, then the criteria are included in the causal digraph, and if otherwise, the criteria are excluded. The criteria included in the causal digraph are the criteria that have a significant effect on other criteria.

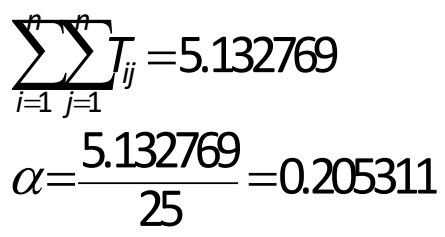

Step 6. Producing the causal digraph

The causal digraph in Figure 4 is produced by using excel solver using the coordinates of the cause-effect group ( $D+R, D-R)$ obtained from Table 14. The arrows in Figure 4 show the relationship of elements in matrix $T$, which are the gold-coloured and bold elements in Table 13 , are greater than $\alpha$. For example, $T_{11}(0.355932)$ is greater than $\alpha(0.205311)$, thus, the arrow from $\mathrm{C} 1$ to $\mathrm{C} 2, \mathrm{C} 3$ and $\mathrm{C} 4$ in Figure 3 indicates that $\mathrm{C} 1$ affects $\mathrm{C2}, \mathrm{C} 3$, and C4. The same goes for other elements in matrix $T$ that have greater value than $\alpha$. Based on Figure 4, warranty (C4) has a negative value of $D-R$ which is -0.918079096 meaning that this criterion can easily get influenced by other criteria and was placed in the effect group. While cost (C1), quality (C2), relationship with the supplier (C3), and machinery safety (C5) criteria are in the cause group as all these criteria have a $D$ - $R$ positive value which means that all criteria can influence warranty (C4) and since quality (C2) has the highest D - R positive value, it has a dominating influence on other criteria. $D+R$ shows the degree of dependency between criteria and based on Figure 4, quality (C2) is the criterion that has the highest dependencies with other criteria as it holds the highest $D+R$ value followed by cost $(C 1)$, machinery safety (C5), relationship with the supplier (C3) and warranty (C4) in the second, third, fourth and fifth place respectively. 


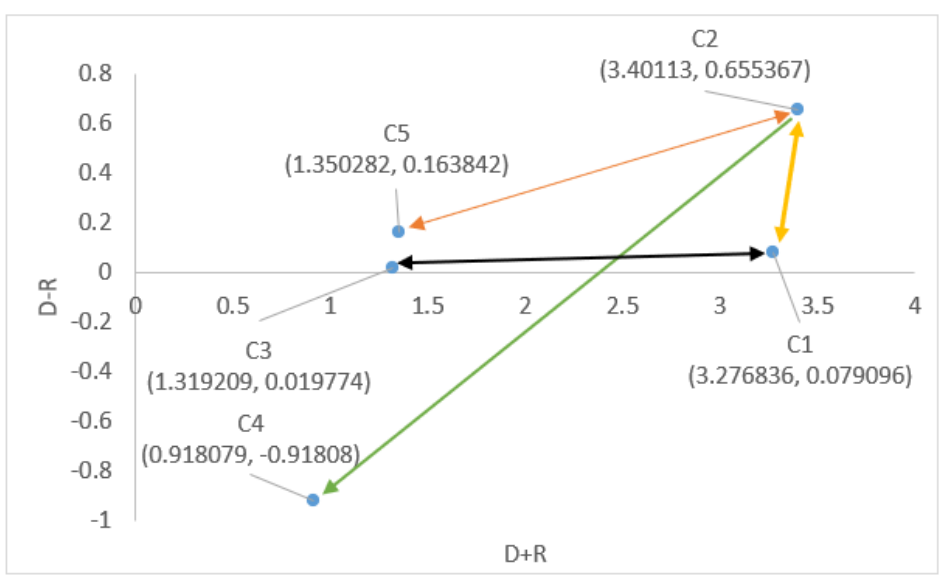

Figure 4. The Causal Digraph

This concludes that both of AHP and DEMATEL method has its own strength that can emphasize the qualities of each method by integrating this method together. Thus, to achieve the objectives of this study, the integrated AHP-DEMATEL method is used.

\section{Results and Discussion}

In this chapter, the findings will be discussed.

\section{Results of AHP Method}

Table 15. Weight and Ranking Order of Criteria

\begin{tabular}{|c|c|c|c|c|}
\hline \multirow[t]{2}{*}{ Criteria } & & \multicolumn{2}{|c|}{ AHP method } & \multirow{2}{*}{$\begin{array}{l}\text { Decision-maker's } \\
\text { choice } \\
\text { Rank }\end{array}$} \\
\hline & & $\begin{array}{l}\text { Weight } \\
\text { (\%) }\end{array}$ & Rank & \\
\hline C1 & Cost & 36 & 1 & 1 \\
\hline C2 & Quality & 23 & 3 & 2 \\
\hline C3 & $\begin{array}{l}\text { Relationship with the } \\
\text { supplier }\end{array}$ & 5 & 5 & 5 \\
\hline C4 & Warranty & 9 & 4 & 4 \\
\hline C5 & Machinery safety & 27 & 2 & 3 \\
\hline
\end{tabular}

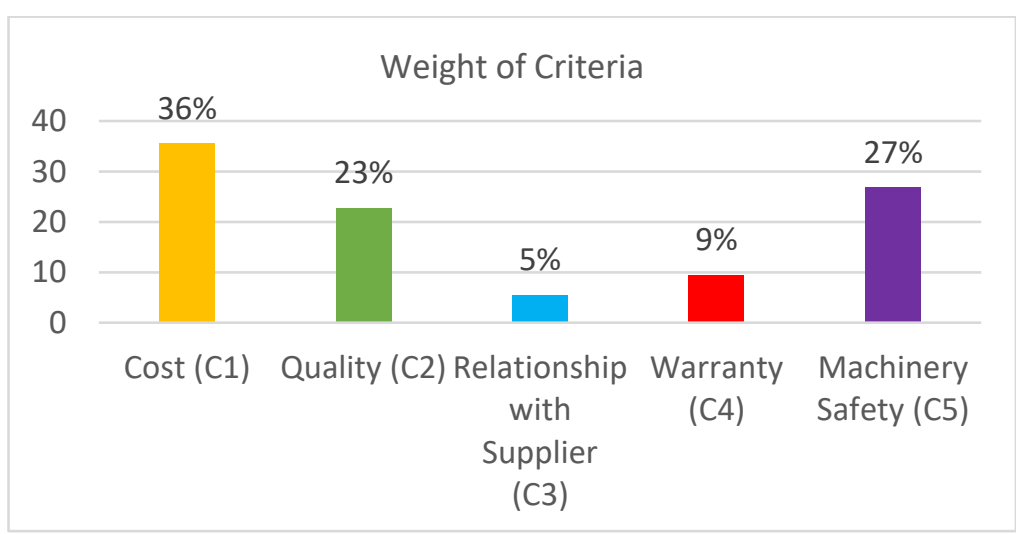

Figure 5. Weight of Criteria 
Figure 5 and Table 15 show the weight and ranking order for each criterion. The findings show that the ranking order for criteria using the AHP method is $\mathrm{C} 1>\mathrm{C} 5>\mathrm{C} 2>\mathrm{C} 4>\mathrm{C} 3$ and the decision maker's choices is $\mathrm{C} 1>\mathrm{C} 2>\mathrm{C} 5>\mathrm{C} 4>\mathrm{C} 3$ and thus, this support the findings as the most preferred criterion in selecting the best supplier for printing machine is cost (C1) while the least preferred criterion is the relationship with the supplier (C3). Obtaining a high revenue is the common goal for any business and therefore, to achieve the high revenue goal the company needs a large market share (Bauer \& Colgan, 2001). The large market share can be achieved by lowering the price of the products leading to the high demand for products (Helms et al., 1997). Hence, it is important to consider the cost (C1) criterion properly before selecting a supplier. Supplier Relationship Management (SRM) system handles the company relationships with the supplier (Park et al., 2010) and helps to form strategic relationships with the suppliers to attain long-term goals (Chandra \& Kumar, 2000). In other words, the relationship with the supplier (C3) criterion can be taken less into account when selecting the best supplier for printing machine as SRM are more focused on collaboration with suppliers, and the relationships with suppliers are usually handled by the SRM (Park et al., 2010). Since selecting the best supplier for the company is the main objective of the study, the decisionmaker decides to focus on other criteria more than the relationship with supplier (C3) criterion. The consistency ratio for the criteria is $8 \%<10 \%$ and therefore, the decision maker's judgment is consistent.

Table 16. Weight and Ranking Order of Alternatives

\begin{tabular}{llll}
\hline Supplier & AHP method & $\begin{array}{l}\text { Decision-maker's } \\
\text { choice }\end{array}$ \\
\cline { 2 - 4 } & Weight (\%) & Rank & Rank \\
\hline S1 & 17.23 & 3 & 2 \\
S2 & 49.63 & 1 & 1 \\
S3 & 33.14 & 2 & 3 \\
\hline
\end{tabular}

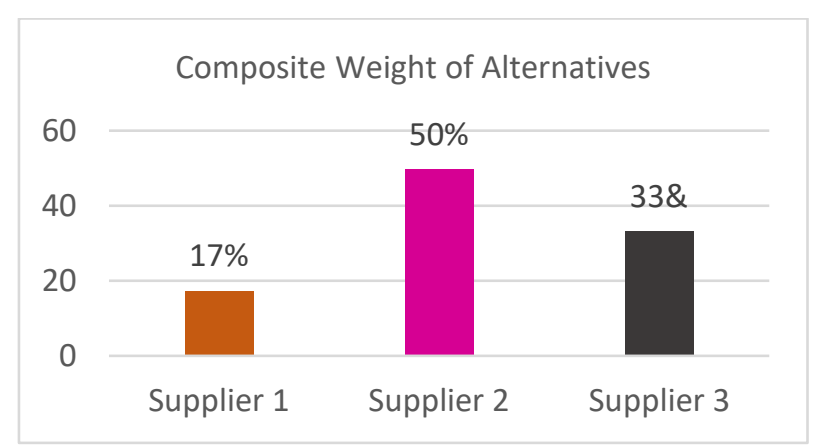

Figure 6. Composite Weight of Alternatives

Based on Figure 6 and Table 16, the ranking order of alternatives by using the AHP method is $\mathrm{S} 2>\mathrm{S} 3>\mathrm{S} 1$ and the decision maker's choices are S2 > S1 > S3. Based on the findings, S2 is the most preferred supplier corresponds to the decision maker's choices. S2 has the highest percentage of weight because the weight of cost (C1), relationship with the supplier (C3), and warranty (C4) criteria were the highest for $\$ 2$ compared to other suppliers. Decisionmaker has been dealing with S2 for one year, and based on the decision-maker, the cost of the printing machines offered by $\mathrm{S} 2$ is affordable along the quality of the machines is the same as the other suppliers. The findings are acceptable as it corresponds with the decision maker's choices in which S2 is the best supplier for the printing machine. The least preferred supplier 
obtained, does not correspond with the decision maker's choices. The decision-maker rank S3 as the least preferred because of the expensive cost offered by S3. It is possible that the choices made by the decision-maker before and after using the AHP method are different as human judgment is always unclear. Hence, using the AHP method can help the decisionmaker to rank and select the best alternative when multiple criteria were considered.

\section{Results of DEMATEL Method}

Table 17. The Direct and Indirect Effect of the Criteria

\begin{tabular}{lllll}
\hline Criteria & $\begin{array}{l}\text { D } \\
\text { (Prominence) }\end{array}$ & $\begin{array}{l}\text { R } \\
\text { (Relation) }\end{array}$ & $\begin{array}{l}\text { R } \\
\text { Effect/ } \\
\text { Cause }\end{array}$ \\
\hline Cost (C1) & 3.276836 & 0.079096 & Cause \\
Quality (C2) & 3.40113 & 0.655367 & Cause \\
Relationship with Supplier & 1.319209 & 0.019774 & Cause \\
(C3) & & & \\
Warranty (C4) & 0.918079 & -0.91808 & Effect \\
Machinery Safety (C5) & 1.350282 & 0.163842 & Cause \\
\hline
\end{tabular}

Table 17 shows the direct and indirect effects of the criteria where $\mathrm{C} 1, \mathrm{C} 2, \mathrm{C} 3$, and $\mathrm{C} 5$ are in the cause group, while $\mathrm{C} 4$ is in the effect group because of its negative value in $\mathrm{D}-\mathrm{R}$ column.

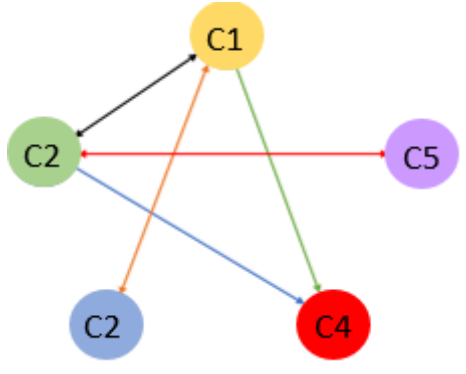

Figure 7. The Causal Relation among Criteria

The relationship between criteria was evaluated using the DEMATEL method. Based on Table 17, criteria that were classified in cause group were cost (C1), quality (C2), relationship with supplier (C3), and machinery safety (C5) due to the positive values in $D-R$, while the criteria that belong in the effect group was only warranty $(\mathrm{C} 4)$ criterion based on the negative values in D - R. The criteria in cause group influenced criteria in the effect group (Raut et al., 2011; Xia et al., 2015) and as shown in Figure 7, there are no criteria that were influenced by warranty (C4) criterion but instead it was the one being influenced by cost (C1) and quality (C2) criteria. Aside from that, the DEMATEL method yielded quality (C2) as the most influential criterion as the $D+R$ value is the highest while warranty (C4) as the lowest of influence criterion as the $D+R$ value is the least among other criteria. Based on Figure 7 , the quality (C2) criterion influenced the other three criteria. This means that if the decision-maker focuses more on the quality of the machine when selecting the supplier, the other four criteria will also be focused automatically especially for the criteria in the effect group where it can be easily influenced by the other criteria in the cause group (Falatoonitoosi et al., 2013).

\section{Conclusion}

This study is using the integrated AHP and DEMATEL method to select the best supplier and determine the interrelationship between criteria in such complex environments. By using the 
AHP method, the findings show that the ranking order for the criteria is $\mathrm{C} 1>\mathrm{C} 5>\mathrm{C} 2>\mathrm{C} 4>$ C3 where the most important criterion in selecting the best supplier is the cost (C1) criterion and the least important criterion is the relationship with the supplier (C3) criterion. The best supplier is obtained after considering five criteria at once. The ranking order is S2 > S3 > S1 with Supplier 2 (S2) as the best printing machine supplier but the second and the third ranking differs from the decision maker's choices. As for the findings of the DEMATEL method, the quality (C2) criterion has the strongest connection and gives the most influence on other criteria in which the most influential criteria could directly or indirectly influence other criteria (Mohd et al., 2020). This proves the objectives of this study which are to select the best supplier using the AHP method and determining the interrelationship among criteria using the DEMATEL method have been achieved. In this study, the proposed method can be used to select the best alternative with multiple criteria. However, the greater the number of criteria and alternatives added in the implementation of the AHP method, the more timeconsuming it is in obtaining the result. As for the DEMATEL method, the interrelationship among the criteria is proven by classifying the criteria into cause and effect groups, and with the help of threshold value, it assists the decision-maker to identify which criteria have a significant effect and eliminate the insignificant effect to improve the supplier's performance for a long-term (Balsara et al., 2019).

The application of this method which is the AHP-DEMATEL method is not limited to just supplier selection, but it is also applicable to other real-life problems such as the allied hospitals' selection problem, the selection of new personnel, and the climate change mitigation strategies problem. This study recommends using this method to solve any selection problems. However, since the information obtained is always uncertain, vague, and imprecise, then it is also recommended to use the integrated method of Fuzzy AHP and Fuzzy DEMATEL method. If the judgments cannot be directly expressed by crisp values, it is beneficial to use the method under a fuzzy environment (Kilincci \& Onal, 2011). Fuzzy Set Theory can deal with the uncertainty and ambiguity of the evaluation process. Linguistic terms of fuzzy sets are used to developed Fuzzy Set Theory based on the key elements in human thought (Shahraki \& Paghaleh, 2011). In addition, the usage of other MCDM methods such as MOORA that uses the statistical method in selecting the best alternative (Patnaik et al., 2020), Intuitionistic Fuzzy TOPSIS that involves less complicated calculations and is easy to implement (Kabayadi, 2020), or any other combination of MCDM methods can be beneficial for future research or studies.

\section{Acknowledgements}

This paper is a work under Universiti Teknologi MARA Cawangan Negeri Sembilan, Kampus Seremban.

We thank our colleagues, families, and friends for the support.

\section{References}

Abdul Rashid, N. S., Amin, M. N. A., \& Mahad, N. F. (2020). Application of Fuzzy Analytic Hierarchy Process For Contractor Selection Problem. Journal of Science and Technology, $3(2), 258-276$.

Balsara, S., Jain, P. K., \& Ramesh, A. (2019). An integrated approach using AHP and DEMATEL for evaluating climate change mitigation strategies of the Indian cement manufacturing industry. Environmental Pollution, 252, 863-878.

Bauer, C., \& Colgan, J. (2001). Planning for electronic commerce strategy: an explanatory 
study from the financial services sector. Logistics Information Management, 14(1/2), 2432.

Campos, M., Jimenez, F., Sanchez, G., Juarez, J. M., Morales, A., Canovas-Segura, B., \& Palacios, F. (2020). A methodology based on multiple criteria decision analysis for combining antibiotics in empirical therapy. Artificial Intelligence in Medicine, 102, 101751.

Chandra, C., \& Kumar, S. (2000). Supply chain management in theory and practice: A passing fad or a fundamental change? Industrial Management and Data Systems, 100(3), 100113.

Chang, C. W., Wu, C. R., Lin, C. T., \& Chen, H. C. (2007). An application of AHP and sensitivity analysis for selecting the best slicing machine. Computers and Industrial Engineering, 52(2), 296-307.

Cheraghi, S. H., Dadashzadeh, M., \& Subramanian, M. (2004). Critical Success Factors For Supplier Selection: An Update. Journal of Applied Business Research (JABR), 20(2), 91108.

Dalvi-Esfahani, M., Niknafs, A., Kuss, D. J., Nilashi, M., \& Afrough, S. (2019). Social media addiction: Applying the DEMATEL approach. Telematics and Informatics, 43, 101250.

Demirel, H., Şener, B., Yildiz, B., \& Balin, A. (2020). A real case study on the selection of suitable roll stabilizer type for motor yachts using hybrid fuzzy AHP and VIKOR methodology. Ocean Engineering, 217, 108125.

Falatoonitoosi, E., Leman, Z., Sorooshian, S., \& Salimi, M. (2013). Decision-making trial and evaluation laboratory. Research Journal of Applied Sciences, Engineering and Technology, 5(13), 3476-3480.

Gharakhani, D. (2012). The Evaluation of Supplier Selection Criteria by Fuzzy DEMATEL Method. Journal of Basic and Application Scientific Research, 2(4), 3215-3224.

Hashmi, N., Jalil, S. A., \& Javaid, S. (2021). Carbon footprint based multi-objective supplier selection problem with uncertain parameters and fuzzy linguistic preferences. Sustainable Operations and Computers, 2, 20-29.

Helms, M. M., Dibrell, C., \& Wright, P. (1997). Competitive strategies and business performance: evidence from the adhesives and sealants industry. Management Decision, 35(9), 689-703.

Hendriks, M. M. W. B., de Boer, J. H., Smilde, A. K., \& Doornbos, D. A. (1992). Multicriteria decision making. In Chemometrics and Intelligent Laboratory Systems (Vol. 16, Issue 3).

Ishizaka, A., \& Labib, A. (2009). Analytic Hierarchy Process and Expert Choice: Benefits and limitations. OR Insight, 22(4), 201-220.

Kabadayi, N. (2020). An Integrated Fuzzy DEMATEL and Intuitionistic Fuzzy TOPSIS Method to Evaluate Sustainable Suppliers. Alphanumeric Journal, 8(2), 201-226.

Karthikeyan, R., Venkatesan, K. G. S., \& Chandrasekar, A. (2017). A Comparison of strength and weakness for analytical hierarchy process. International Journal of Pure and Applied Mathematics, 116(8), 29-33.

Kilincci, O., \& Onal, S. A. (2011). Fuzzy AHP approach for supplier selection in a washing machine company. Expert Systems with Applications, 38(8), 9656-9664.

Kumar, K. (2018). A Spectrum Handoff Scheme for Optimal Network Selection in NEMO based Cognitive Radio Vehicular Networks: A Cost Function MADM Method based on Grey Theory based Approach. Procedia Computer Science, 125, 275-281.

Li, T., Li, A., \& Guo, X. (2020). The sustainable development-oriented development and utilization of renewable energy industry--A comprehensive analysis of MCDM methods. 
Energy, 212, 118694.

Liou, J. J. H., \& Tzeng, G. H. (2012). Comments on "Multiple criteria decision making (MCDM) methods in economics: An overview." Technological and Economic Development of Economy, 18(4), 672-695.

Liu, Y., Eckert, C. M., \& Earl, C. (2020). A review of fuzzy AHP methods for decision-making with subjective judgements. Expert Systems with Applications, 161, 113738.

Maqbool, A., \& Khan, N. Z. (2020). Analyzing barriers for implementation of public health and social measures to prevent the transmission of COVID-19 disease using DEMATEL method. Diabetes and Metabolic Syndrome: Clinical Research and Reviews, 14(5), 887892.

Mau-Crimmins, T., De Steiguer, J. E., \& Dennis, D. (2005). AHP as a means for improving public participation: A pre-post experiment with university students. Forest Policy and Economics, 7(4), 501-514.

Mohd, A. H., Ramli, N., Nassir, A. A., Hazirah, N., \& Bahkri, M. (2020). Analysing Supplier Selection Criteria in Fertigation System Using Fuzzy Dematel Method. Gading Journal of Science and Technology, 3(1), 42-51.

Nadkarni, R. R., \& Puthuvayi, B. (2020). A comprehensive literature review of Multi-Criteria Decision Making methods in heritage buildings. Journal of Building Engineering, 32, 101814.

Najmi, A., \& Makui, A. (2010). Providing hierarchical approach for measuring supply chain performance using AHP and DEMATEL methodologies. International Journal of Industrial Engineering Computations, 1(2), 199-212.

Ngai, E. W. T., \& Chan, E. W. C. (2005). Evaluation of knowledge management tools using AHP. Expert Systems with Applications, 29(4), 889-899.

Ortíz, M. A., Cómbita, J. P., La De Hoz, Á. A., De Felice, F., \& Petrillo, A. (2016). An integrated approach of AHP-DEMATEL methods applied for the selection of allied hospitals in outpatient service. International Journal of Medical Engineering and Informatics, 8(2), 87-107.

Park, J., Shin, K., Chang, T. W., \& Park, J. (2010). An integrative framework for supplier relationship management. Industrial Management and Data Systems, 110(4), 495-515.

Patnaik, P. K., Swain, P. T. R., Mishra, S. K., Purohit, A., \& Biswas, S. (2020). Composite material selection for structural applications based on AHP-MOORA approach. Materials Today: Proceedings, 33, 5659-5663.

Qi, R., Li, S., Qu, L., Sun, L., \& Gong, C. (2020). Critical factors to green mining construction in China: A two-step fuzzy DEMATEL analysis of state-owned coal mining enterprises. Journal of Cleaner Production, 273, 122852.

Raut, R. D., Bhasin, H. V., \& Kamble, S. S. (2011). Evaluation of supplier selection criteria by combination of AHP and fuzzy DEMATEL method. International Journal of Business Innovation and Research, 5(4), 359-392.

Saaty, R. W. (1987). The analytic hierarchy process-what it is and how it is used. Mathematical Modelling, 9(3-5), 161-176.

Saaty, T. L. (1990). How to make a decision: The Analytic Hierarchy Process. European Journal of Operational Research, 48(1), 9-26.

Saaty, T. L. (2000). Fundamentals of Decision Making and Priority Theory With the Analytic Hierarchy Process. RWS Publications.

Shahraki, A. R., \& Paghaleh, M. J. (2011). Ranking the voice of customer with fuzzy DEMATEL and fuzzy AHP. Indian Journal of Science and Technology, 4(12), 1763-1772. 
Shieh, J. I., Wu, H. H., \& Huang, K. K. (2010). A DEMATEL method in identifying key success factors of hospital service quality. Knowledge-Based Systems, 23(3), 277-282.

Solangi, Y. A., Tan, Q., Mirjat, N. H., \& Ali, S. (2019). Evaluating the strategies for sustainable energy planning in Pakistan: An integrated SWOT-AHP and Fuzzy-TOPSIS approach. Journal of Cleaner Production, 236, 117655.

Sumrit, D., \& Anuntavoranich, P. (2013). Using DEMATEL Method to Analyze the Causal Relations on Technological Innovation Capability Evaluation Factors in Thai TechnologyBased Firms. International Transaction Journal of Engineering, Management, \& Applied Sciences \& Technologies, 4(2), 81-103.

Tashayo, B., Honarbakhsh, A., Akbari, M., \& Eftekhari, M. (2020). Land suitability assessment for maize farming using a GIS-AHP method for a semi-arid region, Iran. Journal of the Saudi Society of Agricultural Sciences, 19(5), 332-338.

Vaidya, O. S., \& Kumar, S. (2006). Analytic hierarchy process: An overview of applications. European Journal of Operational Research, 169(1), 1-29.

Velasquez, M., \& Hester, T. P. (2013). An Analysis of Multi-Criteria Decision Making Methods. International Journal of Operations Research, 10(2), 56-66.

Xia, X., Govindan, K., \& Zhu, Q. (2015). Analyzing internal barriers for automotive parts remanufacturers in China using grey-DEMATEL approach. Journal of Cleaner Production, 87(1), 811-825.

Yasmin, M., Tatoglu, E., Kilic, H. S., Zaim, S., \& Delen, D. (2020). Big data analytics capabilities and firm performance: An integrated MCDM approach. Journal of Business Research, 114, 1-15.

Yazdi, M., Khan, F., Abbassi, R., \& Rusli, R. (2020). Improved DEMATEL methodology for effective safety management decision-making. Safety Science, 127, 104705.

Zhang, G., \& Lu, J. (2009). A linguistic intelligent user guide for method selection in multiobjective decision support systems. Information Sciences, 179(14), 2299-2308. 